\title{
Cytoreductive Nephrectomy and Overall Survival of Patients with Metastatic Renal Cell Carcinoma Treated with Targeted Therapy-Data from the National Renis Registry
}

\author{
Alexandr Poprach ${ }^{1,2}, *$, Milos Holanek ${ }^{1,2}$, Renata Chloupkova ${ }^{3}$, Radek Lakomy ${ }^{1,2}$, \\ Michal Stanik ${ }^{4}$, Ondrej Fiala ${ }^{5}$, Bohuslav Melichar ${ }^{6,7}$, Katerina Kopeckova ${ }^{8}$, \\ Milada Zemanova ${ }^{9} \mathbb{D}$, Igor Kiss ${ }^{1,2}$, Igor Penka ${ }^{10}$, Julia Bohosova ${ }^{11}$ and Tomas Buchler 12 \\ 1 Department of Comprehensive Cancer Care, Masaryk Memorial Cancer Institute, 65653 Brno, \\ Czech Republic; holanek@mou.cz (M.H.); lakomy@mou.cz (R.L.); kiss@mou.cz (I.K.) \\ 2 Department of Comprehensive Cancer Care, Faculty of Medicine, Masaryk University, 62500 Brno, \\ Czech Republic \\ 3 Institute of Biostatistics and Analyses, Faculty of Medicine, Masaryk University, 62500 Brno, \\ Czech Republic; chloupkova@iba.muni.cz \\ 4 Department of Urologic Oncology, Masaryk Memorial Cancer Institute and Masaryk University, 65653 Brno, \\ Czech Republic; stanik@mou.cz \\ 5 Department of Oncology, University Hospital, 32300 Pilsen, Czech Republic; ondrej.fiala@fnplzen.cz \\ 6 Department of Oncology, Palacky University Medical School and Teaching Hospital, 77900 Olomouc, \\ Czech Republic; Bohuslav.melichar@upol.cz \\ 7 University Hospital in Hradec Kralove, 50005 Hradec Kralove, Czech Republic \\ 8 Department of Oncology, Motol University Hospital and 2nd Faculty of Medicine Charles University, \\ 15006 Prague, Czech Republic; katerina.kopeckova@fnmotol.cz \\ 9 Department of Oncology, First Faculty of Medicine Charles University and General University Hospital, \\ 12000 Prague, Czech Republic; milada.zemanova@vfn.cz \\ 10 Department of Surgery, University Hospital Bohunice, Faculty of Medicine, Masaryk University, 62500 Brno, \\ Czech Republic; penka.igor@fnbrno.cz \\ 11 Central European Institute of Technology (CEITEC), University Campus Bohunice, Masaryk University, \\ 62500 Brno, Czech Republic; julia.bohosova@ceitec.muni.cz \\ 12 Department of Oncology, First Faculty of Medicine, Thomayer Hospital and Charles University, \\ 14059 Prague, Czech Republic; tomas.buchler@ftn.cz \\ * Correspondence: poprach@mou.cz; Tel.: +420-543-131-111
}

Received: 31 August 2020; Accepted: 8 October 2020; Published: 10 October 2020 updates

Simple Summary: The treatment of metastatic renal cell carcinoma is traditionally initiated with the removal of the diseased kidney with the tumor in many patients. However, there is ongoing controversy about the benefit of kidney removal if targeted therapy is used. The present paper analyses a large cohort of patients, and the results indicate that primary tumor removal should still be strongly considered in patients who are treated with targeted therapies.

\begin{abstract}
The role of cytoreductive nephrectomy $(\mathrm{CN})$ in treatment of locally advanced or metastatic renal cell carcinoma ( $\mathrm{mRCC}$ ) in the era of targeted therapies (TT) is still not clearly defined. The study population consisted of 730 patients with synchronous mRCC. The RenIS (Renal carcinoma Information System) registry was used as the data source. The CN/TT cohort included patients having $\mathrm{CN}$ within 3 months from the mRCC diagnosis and subsequently being treated with TT, while the TT cohort included patients receiving TT upfront. Median progression-free survival from the first intervention was 6.7 months in the TT arm and 9.3 months in the CN/TT patients $(p<0.001)$. Median overall survival was 14.2 and 27.2 months, respectively $(p<0.001)$. Liver metastasis, high-grade tumor, absence of CN, non-clear cell histology, and MSKCC (Memorial Sloan-Kettering Cancer Center) poor
\end{abstract}


prognosis status were associated with adverse treatment outcomes. According to the results of this retrospective study, patients who underwent $\mathrm{CN}$ and subsequently were treated with TT had better outcomes compared to patients treated with upfront TT. The results of the study support the use of $\mathrm{CN}$ in the treatment algorithm for mRCC.

Keywords: metastatic renal cell carcinoma; targeted therapy; cytoreductive nephrectomy; overall survival

\section{Introduction}

Cytoreductive nephrectomy $(\mathrm{CN})$ is one of the most controversial interventions in the treatment of metastatic renal cell carcinoma (mRCC). In the cytokine therapy era, $\mathrm{CN}$ was considered a mainstay of treatment for fit patients in cases where it led to substantial reduction of total tumor mass [1-3]. $\mathrm{CN}$ was even reported to result in spontaneous regression of metastases in rare cases $[4,5]$.

The role of $\mathrm{CN}$ is less clear if targeted therapies (TT) are used as systemic agents for mRCC. CARMENA, the only prospective phase III trial studying CN in the context of TT, showed that the omission of $\mathrm{CN}$ and upfront initiation of sunitinib therapy in patients with synchronous mRCC is non-inferior compared to $\mathrm{CN}$ followed by sunitinib [6]. However, the CARMENA trial has been criticized and the conclusions have not been universally accepted [7], partly because of the contradiction with large retrospective studies [8-11] and meta-analyses [12-14]. The CARMENA study suffered from slow accrual that led to premature closure after the second interim analysis. Subsequently, the Steering Committee approved the results of the first interim analysis to be used as the overall trial results. In addition, as many as $44 \%$ of patients in the $\mathrm{CN}$-sunitinib arm and $41.5 \%$ of patients in the sunitinib-only arm had poor risk features as defined by the Memorial Sloan Kettering Cancer Center (MSKCC) prognostic criteria [15], whereas the benefit of $\mathrm{CN}$ had only been postulated for intermediate-prognosis patients in previous reports $[9,16,17]$. Importantly, the majority of patients enrolled in CARMENA had a relatively high metastatic burden with the median of two metastatic sites. Furthermore, $17 \%$ of patients randomized to the sunitinib-only arm eventually underwent $\mathrm{CN}$ and, in the other study arm, in $7 \%$ of patients, $\mathrm{CN}$ was planned but not carried out. All these patients were included in the published analysis [6].

In the present retrospective study using data from the RenIS registry, we analyzed data of patients with de-novo mRCC treated with TT who underwent $\mathrm{CN}$ within three months of diagnosis and compared their progression-free survival (PFS) and OS (overall survival) with patients who did not have $\mathrm{CN}$ and were treated with TT only. In addition, intermediate-risk patients were analyzed per number of MSKCC risk factors.

\section{Results}

\subsection{Patient Population and Baseline Characteristics}

There were 458 patients with synchronous metastatic disease and $\mathrm{CN} \leq 3$ months post-mRCC diagnosis followed by TT (CN/TT arm) and 272 patients without CN (TT arm). Median age at diagnosis was 64 and 62 years in the CN/TT and TT cohorts, respectively, and 95\% of patients had clear cell renal cell carcinoma histology. Table 1 shows patient baseline characteristics. The site of metastasis is shown in Table S1. 
Table 1. Baseline patient's characteristics.

\begin{tabular}{|c|c|c|c|}
\hline \multirow[b]{2}{*}{ Characteristic } & \multicolumn{2}{|c|}{ Cohort } & \multirow{2}{*}{$p$-Value ${ }^{(1)}$} \\
\hline & $\begin{array}{c}\mathrm{CN} / \mathrm{TT} \\
(n=458)\end{array}$ & $\begin{array}{c}\text { TT } \\
(n=272)\end{array}$ & \\
\hline \multicolumn{4}{|l|}{ Sex, $n(\%)$} \\
\hline Male & $338(73.8)$ & $200(73.5)$ & \multirow[b]{2}{*}{0.931} \\
\hline Female & $120(26.2)$ & $72(26.5)$ & \\
\hline \multicolumn{4}{|l|}{ Age at diagnosis (years) } \\
\hline median (range) & $62(25-83)$ & $64(35-85)$ & 0.006 \\
\hline \multicolumn{4}{|l|}{ Histology, $n(\%)$} \\
\hline Clear cell carcinoma & $431(94.1)$ & $261(96.0)$ & \multirow{5}{*}{0.581} \\
\hline Papillary cell carcinoma & $22(4.8)$ & $8(2.9)$ & \\
\hline Chromophobe cell carcinoma & $2(0.4)$ & $2(0.7)$ & \\
\hline Bellini duct carcinoma & $2(0.4)$ & $0(0.0)$ & \\
\hline Unknown & $1(0.2)$ & $1(0.4)$ & \\
\hline \multicolumn{4}{|l|}{ Primary tumor grade, $n(\%)$} \\
\hline G1-2 well/moderately differentiated & $160(34.9)$ & $161(59.2)$ & \multirow{2}{*}{$<0.001$} \\
\hline G3-4 poorly/non differentiated & $298(65.1)$ & $111(40.8)$ & \\
\hline \multicolumn{4}{|l|}{ MSKCC score } \\
\hline good prognosis & $3(0.7)$ & $7(2.6)$ & \multirow{3}{*}{$<0.001$} \\
\hline intermediate prognosis & $417(91.0)$ & $215(79.0)$ & \\
\hline poor prognosis & $38(8.3)$ & $50(18.4)$ & \\
\hline \multicolumn{4}{|l|}{ MSKCC score-2 categories } \\
\hline good or intermediate prognosis & $420(91.7)$ & $222(81.6)$ & \multirow{2}{*}{$<0.001$} \\
\hline poor prognosis & $38(8.3)$ & $50(18.4)$ & \\
\hline \multicolumn{4}{|l|}{ ECOG PS } \\
\hline $\mathrm{PS}<2$ & $433(94.5)$ & $258(94.9)$ & \multirow{2}{*}{0.999} \\
\hline $\mathrm{PS} \geq 2$ & $25(5.5)$ & $14(5.1)$ & \\
\hline \multicolumn{4}{|l|}{ Calcium } \\
\hline$\leq 2.5 \mathrm{mmol} / \mathrm{L}$ & $422(92.1)$ & $231(84.9)$ & \multirow{2}{*}{0.003} \\
\hline$>2.5 \mathrm{mmol} / \mathrm{L}$ & $36(7.9)$ & $41(15.1)$ & \\
\hline \multicolumn{4}{|l|}{ Hemoglobin } \\
\hline normal & $273(59.6)$ & $147(54.0)$ & \multirow{2}{*}{0.163} \\
\hline$<$ lower limit of normal & $185(40.4)$ & $125(46.0)$ & \\
\hline \multicolumn{4}{|l|}{ Time from diagnosis to target treatment } \\
\hline$\geq 1$ year & $3(0.7)$ & $10(3.7)$ & \multirow{2}{*}{0.006} \\
\hline$<1$ year & $455(99.3)$ & $262(96.3)$ & \\
\hline \multicolumn{4}{|l|}{ LDH } \\
\hline$\leq 1.5 \times$ upper limit of norm & $428(93.4)$ & $229(84.2)$ & \\
\hline$>1.5 \times$ upper limit of norm & $30(6.6)$ & $43(15.8)$ & $<0.001$ \\
\hline Type of first target treatment, $n(\%)$ & & & \\
\hline sunitinib & $361(78.8)$ & $210(77.2)$ & 0.643 \\
\hline pazopanib & $97(21.2)$ & $62(22.8)$ & \\
\hline Age at first target treatment initiation (ye & & & \\
\hline median (range) & $63(25-83)$ & $64(36-85)$ & 0.006 \\
\hline ECOG PS at first target treatment initiation & & & \\
\hline PS 0 & $174(38.0)$ & $49(18.0)$ & $<0.001$ \\
\hline PS 1 & $259(56.6)$ & $209(76.8)$ & \\
\hline PS 2 & $23(5.0)$ & $14(5.1)$ & \\
\hline PS 3 & $2(0.4)$ & $0(0.0)$ & \\
\hline
\end{tabular}

$\mathrm{CN} / \mathrm{TT}$, cytoreductive nephrectomy followed by targeted therapy. TT, targeted therapy only; MSKCC, Memorial Sloan Kettering Cancer Center; ECOG, Eastern Cooperative Oncology Group; PS, performance status; LDH, Lactate dehydrogenase. ${ }^{(1)}$ Fisher exact test or Mann-Whitney test. Bold: statistically significant.

\subsection{Treatment Outcomes}

While the overall response rate (ORR) was similar for the two analyzed cohorts, the disease control rate (DCR) favored the CN/TT patients. In the TT arm, overall response rate (ORR) was $19 \%$, with complete response (CR) and partial response (PR) observed in $0.4 \%$ and $18.5 \%$ of patients, 
respectively. In the CN/TT, ORR was $24.4 \%$ CR (CR 2.9\%, PR 21.4\%). However, the difference in ORR was not statistically significant $(p=0.116$ ). Stable disease was observed in $30.2 \%$ and $35.4 \%$ of patients in the TT and CN/TT arms, respectively. The disease control rate (DCR) was significantly higher in CN patients, reaching $49.2 \%$ and $59.8 \%$ for the TT and CN/TT arm, respectively $(p=0.011)$.

Median PFS was 6.7 months (95\% CI: 5.5-7.8) in the TT arm and 9.3 months (95\%: CI 8.3-10.4) in the CN/TT patients $(p<0.001)$. The median OS was 14.2 months (95\% CI: 12.1-16.2) and 27.2 months (95\% CI: 22.3-32.1), respectively $(p<0.001)$ (Figure 1$)$.
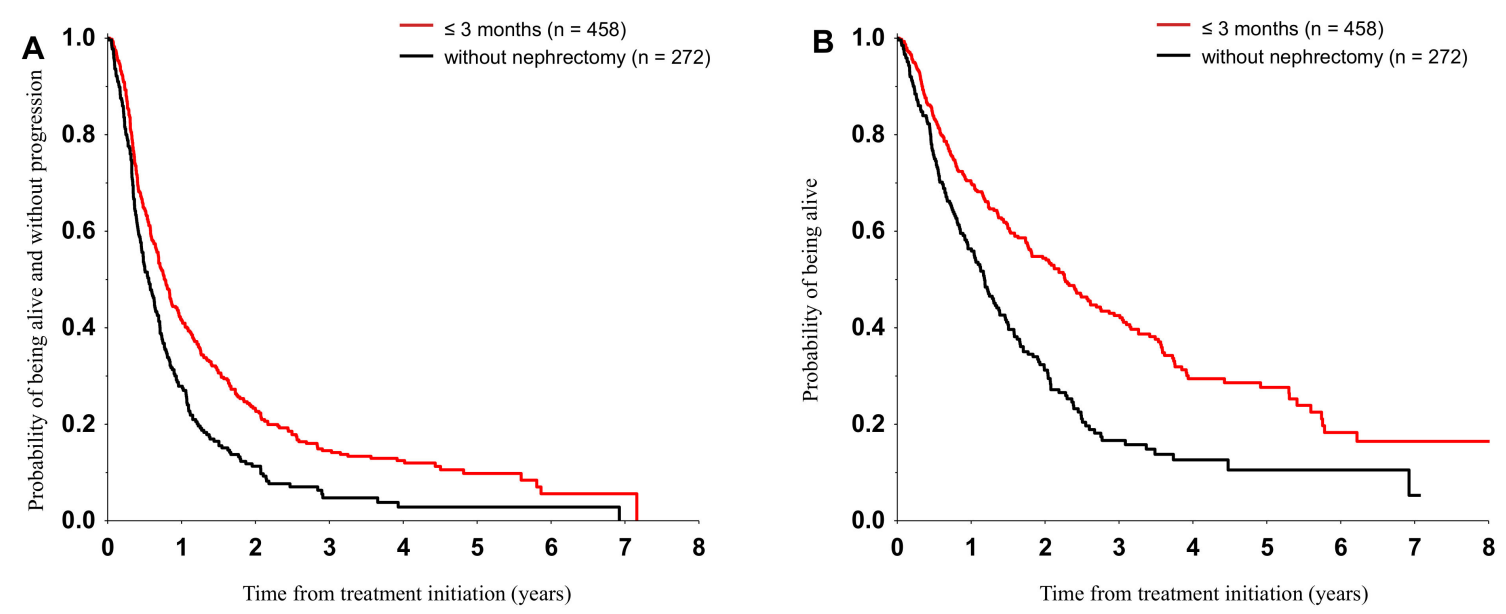

Figure 1. Progression-free (A) and overall survival (B) from first treatment strategy. All the differences were statistically significant at $p<0.001$.

\subsection{Subgroup Analysis}

The benefit of CN on PFS and OS was evident irrespective of age. Patients $\leq 65$ years had a median PFS of 7.6 months (95\% CI: 5.9-7.3) in the TT arm and 8.8 months (95\% CI: 7.3-9.3) in the CN/TT arm. Median OS was 15 months (95\% CI: 12.7-17.2) and 28.7 months (95\% CI: 19.4-38.0) for the TT and $\mathrm{CN} / \mathrm{TT}$, respectively. In patients $>65$ years of age, median PFS was 5.8 months (95\% CI: $4.3-7.3)$ and 10.1 months (95\% CI: 8.0-12.2) and median OS was 12.5 months (8.3-16.6) and 26.3 months $(95 \%$ CI: 20.0-32.5) for the TT and CN/TT cohorts, respectively. All the above differences were statistically significant at $p<0.001$. Age at TT initiation had no statistically significant impact on PFS or OS in the multivariate analysis (Table 2).

Table 2. Progression-free and overall survival results: multivariable Cox-proportional hazards model.

\begin{tabular}{|c|c|c|c|c|c|c|}
\hline \multirow[b]{2}{*}{ Variable } & \multirow[b]{2}{*}{ Category } & \multirow[b]{2}{*}{$n$} & \multicolumn{2}{|c|}{ Progression-Free Survival } & \multicolumn{2}{|c|}{ Overall Survival } \\
\hline & & & $\begin{array}{c}\text { HR } \\
(95 \% \text { CI })\end{array}$ & $\begin{array}{c}\text { Wald Test } \\
p \text {-Value }\end{array}$ & $\begin{array}{c}\text { HR } \\
(95 \% \text { CI) }\end{array}$ & $\begin{array}{c}\text { Wald Test } \\
p \text {-Value }\end{array}$ \\
\hline Nephrectomy & $\mathrm{CN} / \mathrm{TT}$ & 457 & $0.629(0.525-0.755)$ & $<0.001$ & $0.553(0.449-0.681)$ & $<0.001$ \\
\hline \multirow[b]{2}{*}{ Sex } & female & 191 & 1.000 & - & 1.000 & - \\
\hline & male & 537 & $0.881(0.730-1.063)$ & 0.185 & $0.892(0.717-1.109)$ & 0.305 \\
\hline \multirow{2}{*}{ Primary tumor grade } & G1-2 & 319 & 1.000 & - & 1.000 & - \\
\hline & G3-4 & 409 & $1.300(1.093-1.545)$ & 0.003 & $1.453(1.184-1.783)$ & $<0.001$ \\
\hline \multirow[b]{2}{*}{ MSKCC } & good or intermediate & 640 & 1.000 & - & 1.000 & - \\
\hline & poor & 88 & $1.359(1.049-1.761)$ & 0.020 & $1.931(1.455-2.563)$ & $<0.001$ \\
\hline Age at first target & $\leq 65$ years & 425 & 1.000 & - & 1.000 & - \\
\hline treatment initiation & $>65$ years & 303 & $0.956(0.806-1.135)$ & 0.609 & $1.101(0.903-1.344)$ & 0.341 \\
\hline
\end{tabular}

CN/TT, cytoreductive nephrectomy followed by targeted therapy. TT, targeted therapy only; MSKCC, Memorial Sloan Kettering Cancer Center; HR, hazard ratio; CI, confidence interval. Bold: statistically significant. 
Similarly, tumor grade was not a factor that significantly altered the benefit of nephrectomy. Patients with low-grade tumors had PFS of 8.1 months (95\% CI: 6.7-9.5) versus 12 months (95\% CI: 9.0-15.0) and an OS of 19.0 months (95\% CI: 13.2-24.8) versus 31.0 months (95\% CI: 22.1-39.9), while patients with high-grade tumors had PFS of 4.4 months (95\% CI: 3.3-5.6) and 8.3 months (95\% CI: 6.9-9.7), and an OS of 10.1 (95\% CI: 7.6-12.7) and 23.6 months (95\% CI: 17.8-29.4), for the TT and CN/TT cohorts, respectively. All the differences were statistically significant at $p<0.001$ ).

There was a major difference in outcomes between intermediate-risk patients with one versus two risk factors, but both subgroups derived benefit from $\mathrm{CN}$ (Table 3).

Table 3. Progression-free survival and overall survival from first treatment strategy.

\begin{tabular}{|c|c|c|c|c|}
\hline \multirow{2}{*}{ Number of Risk Factors (MSKCC) } & \multirow{2}{*}{ Median PFS and OS } & \multicolumn{2}{|c|}{ Cohort } & \multirow{2}{*}{ Log-Rank Test $p$-Value } \\
\hline & & $\mathrm{CN} / \mathrm{TT}$ & TT & \\
\hline \multirow{2}{*}{$\begin{array}{l}\text { MSKCC } 1 \text { risk factor patients, } \\
\qquad n=328\end{array}$} & Median PFS (95\% CI) & $\begin{array}{c}n=222 \\
10.2 \text { months } \\
(7.8-12.5)\end{array}$ & $\begin{array}{c}n=106 \\
7.7 \text { months } \\
(6.2-9.2)\end{array}$ & 0.002 \\
\hline & Median OS (95\% CI) & $\begin{array}{c}37.9 \text { months } \\
(28.1-47.7) \\
n=195\end{array}$ & $\begin{array}{c}17.5 \text { months } \\
(11.2-23.8) \\
n=109\end{array}$ & $<0.001$ \\
\hline \multirow{2}{*}{$\begin{array}{l}\text { MSKCC } 2 \text { risk factors patients, } \\
\qquad n=304\end{array}$} & Median PFS (95\% CI) & $\begin{array}{l}8.5 \text { months } \\
(6.7-10.4)\end{array}$ & $\begin{array}{l}5.8 \text { months } \\
(4.7-6.8)\end{array}$ & $<0.001$ \\
\hline & Median OS (95\% CI) & $\begin{array}{l}21.9 \text { months } \\
(16.2-27.5)\end{array}$ & $\begin{array}{l}10.3 \text { months } \\
(7.8-12.8)\end{array}$ & $<0.001$ \\
\hline
\end{tabular}

$\mathrm{CN} / \mathrm{TT}$, cytoreductive nephrectomy followed by targeted therapy. TT, targeted therapy only; MSKCC, Memorial Sloan Kettering Cancer Center; OS, overall survival; PFS, progression-free survival. The factors associated with adverse outcome in a multivariate analysis included the presence of liver metastases, grade 3 or 4 tumor, absence of $\mathrm{CN}$, non-clear cell histology, and MSKCC poor prognosis (Table 2). Bold: statistically significant.

\section{Discussion}

The present analysis strongly suggests that $\mathrm{CN}$ is an independent, favorable predictive factor for treatment outcomes in patients with synchronous mRCC treated with TT. We conducted a subanalysis of the effect of $\mathrm{CN}$ on survival in the MSKCC intermediate-risk patients with one or two risk factors. The findings indicate that the benefit of $\mathrm{CN}$ is maintained in patients with adverse risk factors, regardless of age.

The present data are in accordance with other retrospective studies. Heng et al. analyzed 1658 patients with synchronous mRCC treated with TT. Median OS was 9.5 months and 20.6 months in the TT-only and TT/CN patients, respectively. However, the results might have been affected by a more favorable prognostic profile in the CN/TT patients. The study also showed that patients with four or more International Metastatic Renal Cell Carcinoma Database Consortium (IMDC) prognostic factors did not benefit from $\mathrm{CN}$ [9]. Choueiri et al. showed in a similar retrospective study of 314 patients that $\mathrm{CN}$ patients had better OS than non-CN patients (19.8 vs. 9.4 months, respectively). However, again there were imbalances in patient characteristics: $\mathrm{CN}$ patients were younger and had better performance status, lower levels of corrected calcium, and a lower number of metastatic sites. Patients $\geq 75$ years did not benefit from $\mathrm{CN}$, in contrast with present findings suggesting similar benefits from $\mathrm{CN}$ in younger and older patients. Choueiri et al. also confirmed that poor-risk patients as defined by the MSKCC or the IMDC criteria did not benefit from CN [18]. The results of our study further support findings published by Zhao et al. that patients with both high- and low-grade tumors benefit from $\mathrm{CN}$ [19].

Important updates to the CARMENA study after a median follow-up of 61.5 months were presented at the American Society of Clinical Oncology 2019 Annual Meeting. The authors conducted a sub-analysis of IMDC intermediate prognosis patients, focusing on the difference in OS between patients with one versus two prognostic factors, and they explored whether the number of metastatic sites affected patient survival. In an update analysis of the CARMENA trial, patients with one prognostic factor benefited from $\mathrm{CN}$, with the median OS of 31.4 months versus 25.2 months without 
$\mathrm{CN}$ [20], but patients with two IMDC risk factors did not, with median OS of 16.6 months and 31.2 months for patients with versus without $\mathrm{CN}$, respectively. As the interval from RCC diagnosis to the initiation of treatment of less than year is a risk factor in both MSKCC and IMDC models, this is necessarily the single risk factor present in intermediate-risk patients and one risk factor. The first version of MSKCC criteria included previous nephrectomy instead of the treatment-free interval [21]. Thus, nephrectomy "converts" these patients into favorable-risk patients according the original MSKCC model. Patients with two risk factors remain intermediate-risk even after $\mathrm{CN}$ according to the older version of MSKCC classification. Therefore, this result from a prospective study seems to validate the older version of MSKCC if $\mathrm{CN}$ is considered.

SURTIME was another prospective trial, a phase II study aiming to determine whether a period of sunitinib therapy before $\mathrm{CN}$ improves the outcome compared with immediate $\mathrm{CN}$ followed by the same agent. Although the study was underpowered and eventually closed due to poor accrual, the results indicated that deferred $\mathrm{CN}$ may be superior to early $\mathrm{CN}$ followed by sunitinib, with median OS of 32.4 months versus 15.1 months, respectively. In addition, a recent pooled analysis suggested that in intermediate-risk patients, deferred $\mathrm{CN}$ in patients not progressing on first-line vascular endothelial growth factor (VEGF)-directed therapy is superior to immediate $\mathrm{CN}$ followed by systemic treatment [22].

These results are in accordance with a post-hoc analysis of 40 patients in the sunitinib only arm of CARMENA, who, for different reasons, underwent nephrectomy. The OS of the $\mathrm{CN}$ patients was 48.5 months, while it reached 15.7 months in non- $\mathrm{CN}$ patients [20].

To summarize, the results of prospective studies suggest that $\mathrm{CN}$ still plays a role in patients with one IMDC risk factor and that patients not progressing on anti-VEGF therapy may benefit from later $\mathrm{CN}$, although the question of upfront versus deferred $\mathrm{CN}$ remains unresolved and deserves a prospective trial.

Several biological hypotheses have been put forward to explain the apparent benefit of cytoreductive nephrectomy in patients with metastatic disease. RCC is the prime model for spatial tumor heterogeneity. Gerlinger et al. clearly showed that most genetic driver mutations in RCC are subclonal, and only approximately one-third are present in all regions of the primary tumor and metastases $[23,24]$. Therefore, volume reduction may result in removal or limitation of tumor clones that may be resistant to the therapy and represent foci of future progressive disease. Immunological mechanisms may play a role in superior survival of patients with $\mathrm{mRCC}$ after $\mathrm{CN}$, which is associated with decreased systemic inflammation and reversal of cellular immunity abnormalities $[25,26]$. These improvements may be especially advantageous in patients receiving immunotherapies but also play a role with VEGF-targeted therapies [27].

Finally, despite adjustments for established risk factors and the prognostic score, some unmeasurable variables may result in selection bias. These include the physician's subjective view of the patient's general condition and comorbidities, as well as primary tumor properties, the extent and volume of metastatic disease, and surgical variables which are imperfectly represented by the prognostic models [28].

In our opinion supported by the results of the present analysis, patients with good performance status and one to two risk factors should be considered for $\mathrm{CN}$. The case for $\mathrm{CN}$ is further strengthened after the inclusion of novel immunotherapies in mRCC treatment algorithms. In a phase II study analyzing survival and response rates in patients with $\mathrm{mRCC}$ treated with checkpoint inhibitors with/without $\mathrm{CN}$, the treatment response rate and survival were clearly superior in patients after $\mathrm{CN}$ [29]. Few patients in the present cohort were defined as good prognosis, i.e., the interval from the diagnosis to the initiation of therapy was more than one year. These patients obviously had a more indolent disease that might have allowed for waiting on the decision to initiate therapy. However, a slight imbalance in the number of these patients in both cohorts probably had limited impact on the results that actually indicated a better outcome in the $\mathrm{CN}$ cohort that had only three of such patients. 
Single-agent VEGF inhibitors are no longer the first-line treatment of choice for most patients with mRCC. Nevertheless, many issues identified in these studies, including delayed initiation of systemic therapy in exchange for tumor volume reduction, and delaying the emergence of treatment resistance by reducing tumor heterogeneity using $\mathrm{CN}$, remain relevant in the immunotherapy era.

The limitations of our study include the retrospective nature and associated potential bias. The population was not balanced according to the prognostic factors, similar to other retrospective studies, as demonstrated by Bex et al. [17]. Furthermore, inclusion of patients treated in higher lines with checkpoint inhibitors might have affected the survival results. Complete IMDC scoring could be calculated only in about $50 \%$ of patients. Therefore, full analysis of data based on IMDC was not possible. In addition, as pazopanib and sunitinib were not reimbursed by the public health insurance in the Czech Republic for the treatment of poor risk patients, few were included in the present analysis.

\section{Materials and Methods}

\subsection{Study Design and Data Source}

The data were obtained from the RenIS Registry that represents a database of about $95 \%$ of all patients with mRCC treated with TT in the Czech Republic from 2007 to 2018 [30,31]. The database included a total of 4034 patients treated with targeted therapy for mRCC between 2006 and the end of January 2018. Patients with synchronous metastatic disease subsequently treated with first-line TT with pazopanib or sunitinib were included in the analysis. The CN/TT cohort included patients having $\mathrm{CN}$ within 3 months from the mRCC diagnosis and subsequently treated with TT, while the TT cohort included patients receiving TT upfront.

The RenIS registry contains information on the baseline patient characteristics, diagnosis, extent of the disease, baseline laboratory parameters, and type, outcome, and toxicity of treatments. The data were updated twice a year. Further details on the RenIS Registry were published elsewhere [20]. The project has been approved by the Multicenter Ethics Committee of the University Hospital and the Masaryk Memorial Cancer Institute in Brno, Czech Republic.

\subsection{Statistical Analysis}

Descriptive statistics and frequency tables were used to characterize the sample data set. The statistical significance of differences between subgroups was assessed using the Fisher exact test or the Mann-Whitney test.

Overall survival (OS) is defined as the time from the date of first treatment intervention to death due to any cause (i.e., for patients without nephrectomy, OS is computed from the date of the first line target therapy initiation, and for patients with nephrectomy OS is computed from the date of nephrectomy).

Progression-free survival (PFS) is defined as the time from the date of first treatment strategy (analogously to OS) to the date of the first documented progression or death due to any cause.

PFS and OS were estimated using the Kaplan-Meier method, and all point estimates include 95\% confidence intervals $(95 \% \mathrm{CI})$. Statistical significance of differences in survival among subgroups was assessed using the log-rank test.

Multivariable Cox proportional hazards models were used to evaluate the effect of all potential prognostic factors on the survival measures. Statistical significance of hazard ratios was assessed by mean of the Wald test. All statistical tests were performed at a significance level of $\alpha=0.05$.

\section{Conclusions}

According to the results of this retrospective study, good and intermediate prognosis mRCC patients clearly benefited from $\mathrm{CN}$. The benefit was particularly pronounced in patients with a single risk factor. $\mathrm{CN}$ was beneficial irrespective of tumor grade and age. 
Supplementary Materials: The following are available online at http://www.mdpi.com/2072-6694/12/10/2911/s1, Table S1: Metastatic sites at first targeted treatment initiation.

Author Contributions: Conceptualization: A.P., T.B., R.L.; Methodology: A.P., T.B.; Formal Analysis: R.C.; Investigation A.P., M.H., R.C., R.L., M.S., O.F., B.M., K.K., M.Z., I.K., I.P., J.B., T.B.; Resources: A.P., M.H., R.C., R.L., M.S., O.F., B.M., K.K., M.Z., I.K., I.P., J.B., T.B.; Data Curation, A.P., T.B.; Writing-Original Draft Preparation, A.P.; Writing-Review and Editing: all authors; Supervision: A.P., T.B.; Funding Acquisition: A.P., M.H., I.K. All authors have read and agreed to the published version of the manuscript.

Funding: This work was supported in part by the Ministry of Health, Czech Republic-Conceptual Development of Research Organization (MMCI 00209805) and supported by grant NV18-03-00554 and NV19-08-00250 from the Ministry of Health of Czech Republic. The RenIS registry is funded in part by pharmaceutical companies producing targeted agents for renal cancer (Pfizer, Bayer, Glaxo Smith Kline, Roche, and Novartis).

Acknowledgments: We would like to thank the following heads of the comprehensive cancer centers for the permission to use data of patients from their respective regional networks: Martina Chodacka, Chomutov Hospital and Masaryk Hospital in Usti nad Labem; Vaclav Janovsky, Ceske Budejovice Hospital; Otakar Bednarik, University Hospital, Brno; Jana Prausova, Motol University Hospital, Prague; David Feltl, University Hospital, Ostrava; Jindrich Finek, University Hospital, Pilsen; Jiri Petera, University Hospital, Hradec Kralove; Lubomir Slavicek, Jihlava Hospital; Jana Katolicka, St Anna University Hospital, Brno; Rostislav Vyzula, Masaryk Memorial Institute of Oncology, Brno; Jiri Bartos, County Hospital, Liberec; Martin Safanda, Na Homolce Hospital, Prague; Renata Soumarova, Novy Jicin Hospital; Jitka Abrahamova, Thomayer Hospital, Prague; Lubos Petruzelka, General University Hospital, Prague; Milan Kohoutek, T Bata Memorial Hospital, Zlin. We are also indebted to all physicians who provided data for the RenIS registry.

Conflicts of Interest: A.P. received honoraria and research support from Roche, Bristol Myers Squibb, Novartis, Pfizer, and Ipsen unrelated to this project. T.B. received honoraria and research support from Novartis, Pfizer, Roche, Bristol Myers Squibb, and Ipsen. O.F. received honoraria from Roche, Janssen, Glaxo Smith Kline, and Pfizer for consultations and lectures. B.M. received honoraria for speeches and advisory role Roche, Pfizer, BMS, Astellas, Novartis, Bayer, MSD, Merck Serono, Sanofi, Servier, AstraZeneca, Amgen, Janssen, Eisai, E. Lilly, and Pierre Fabre. M.Z. received honoraria and research support from Novartis, Pfizer, Bristol Myers Squibb, MSD, and AstraZeneca. I.K. has received speakers' honoraria from Roche, Merck, and Amgen. Other authors declare no conflicts of interest. The funders had no role in the design of the study; in the collection, analyses, or interpretation of data; in the writing of the manuscript, or in the decision to publish the results.

\section{References}

1. Flanigan, R.C.; Salmon, S.E.; Blumenstein, B.A.; Bearman, S.I.; Roy, V.; McGrath, P.C.; Caton, J.R.J.; Munshi, N.; Crawford, E.D. Nephrectomy followed by interferon alfa-2b compared with interferon alfa-2b alone for metastatic renal-cell cancer. N. Engl. J. Med. 2001, 345, 1655-1659. [CrossRef] [PubMed]

2. Mickisch, G.H.; Garin, A.; van Poppel, H.; de Prijck, L.; Sylvester, R. Radical nephrectomy plus interferon-alfa-based immunotherapy compared with interferon alfa alone in metastatic renal-cell carcinoma: A randomised trial. Lancet (Lond. Engl.) 2001, 358, 966-970. [CrossRef]

3. Flanigan, R.C.; Mickisch, G.; Sylvester, R.; Tangen, C.; Van Poppel, H.; Crawford, E.D. Cytoreductive nephrectomy in patients with metastatic renal cancer: A combined analysis. J. Urol. 2004, 171, 1071-1076. [CrossRef] [PubMed]

4. Marcus, S.G.; Choyke, P.L.; Reiter, R.; Jaffe, G.S.; Alexander, R.B.; Linehan, W.M.; Rosenberg, S.A.; Walther, M.M. Regression of metastatic renal cell carcinoma after cytoreductive nephrectomy. J. Urol. 1993, 150, 463-466. [CrossRef]

5. Melichar, B.; Vanecková, J.; Morávek, P.; Urminská, H.; Podhola, M. Spontaneous regression of renal cell carcinoma lung metastases in a patient with psoriasis. Acta Oncol. 2009, 48, 925-927. [CrossRef]

6. Mejean, A.; Ravaud, A.; Thezenas, S.; Colas, S.; Beauval, J.-B.; Bensalah, K.; Geoffrois, L.; Thiery-Vuillemin, A.; Cormier, L.; Lang, H.; et al. Sunitinib Alone or after Nephrectomy in Metastatic Renal-Cell Carcinoma. N. Engl. J. Med. 2018. [CrossRef]

7. Massari, F.; Di Nunno, V.; Gatto, L.; Santoni, M.; Schiavina, R.; Cosmai, L.; Brunocilla, E.; Ardizzoni, A.; Porta, C. Should CARMENA Really Change our Attitude Towards Cytoreductive Nephrectomy in Metastatic Renal Cell Carcinoma? A Systematic Review and Meta-Analysis Evaluating Cytoreductive Nephrectomy in the Era of Targeted Therapy. Target. Oncol. 2018, 13, 705-714. [CrossRef] 
8. Hanna, N.; Sun, M.; Meyer, C.P.; Nguyen, P.L.; Pal, S.K.; Chang, S.L.; de Velasco, G.; Trinh, Q.-D.; Choueiri, T.K. Survival Analyses of Patients with Metastatic Renal Cancer Treated with Targeted Therapy with or without Cytoreductive Nephrectomy: A National Cancer Data Base Study. J. Clin. Oncol. Off. J. Am. Soc. Clin. Oncol. 2016, 34, 3267-3275. [CrossRef]

9. Heng, D.Y.C.; Wells, J.C.; Rini, B.I.; Beuselinck, B.; Lee, J.-L.; Knox, J.J.; Bjarnason, G.A.; Pal, S.K.; Kollmannsberger, C.K.; Yuasa, T.; et al. Cytoreductive nephrectomy in patients with synchronous metastases from renal cell carcinoma: Results from the International Metastatic Renal Cell Carcinoma Database Consortium. Eur. Urol. 2014, 66, 704-710. [CrossRef]

10. Conti, S.L.; Thomas, I.-C.; Hagedorn, J.C.; Chung, B.I.; Chertow, G.M.; Wagner, T.H.; Brooks, J.D.; Srinivas, S.; Leppert, J.T. Utilization of cytoreductive nephrectomy and patient survival in the targeted therapy era. Int. J. Cancer 2014, 134, 2245-2252. [CrossRef]

11. Abern, M.R.; Scosyrev, E.; Tsivian, M.; Messing, E.M.; Polascik, T.J.; Dudek, A.Z. Survival of patients undergoing cytoreductive surgery for metastatic renal cell carcinoma in the targeted-therapy era. Anticancer Res. 2014, 34, 2405-2411.

12. García-Perdomo, H.A.; Zapata-Copete, J.A.; Castillo-Cobaleda, D.F. Role of cytoreductive nephrectomy in the targeted therapy era: A systematic review and meta-analysis. Investig. Clin. Urol. 2018, 59, 2-9. [CrossRef] [PubMed]

13. Klatte, T.; Fife, K.; Welsh, S.J.; Sachdeva, M.; Armitage, J.N.; 'Aho, T.; Riddick, A.C.; Matakidou, A.; Eisen, T.; Stewart, G.D. Prognostic effect of cytoreductive nephrectomy in synchronous metastatic renal cell carcinoma: A comparative study using inverse probability of treatment weighting. World J. Urol. 2018, 36, 417-425. [CrossRef]

14. Petrelli, F.; Tomasello, G.; Borgonovo, K.; Ghidini, M.; Turati, L.; Dallera, P.; Passalacqua, R.; Sgroi, G.; Barni, S. Prognostic Survival Associated With Left-Sided vs Right-Sided Colon Cancer. JAMA Oncol. 2017, 3. [CrossRef] [PubMed]

15. Motzer, R.J.; Bacik, J.; Murphy, B.A.; Russo, P.; Mazumdar, M. Interferon-alfa as a comparative treatment for clinical trials of new therapies against advanced renal cell carcinoma. J. Clin. Oncol. 2002, 20, $289-296$. [CrossRef]

16. Mathieu, R.; Pignot, G.; Ingles, A.; Crepel, M.; Bigot, P.; Bernhard, J.C.; Joly, F.; Guy, L.; Ravaud, A.; Azzouzi, A.R.; et al. Nephrectomy improves overall survival in patients with metastatic renal cell carcinoma in cases of favorable MSKCC or ECOG prognostic features. Urol. Oncol. 2015, 33, 339.e9-339.e15. [CrossRef] [PubMed]

17. Bex, A.; Ljungberg, B.; van Poppel, H.; Powles, T. The Role of Cytoreductive Nephrectomy: European Association of Urology Recommendations in 2016. Eur. Urol. 2016, 70, 901-905. [CrossRef] [PubMed]

18. Choueiri, T.K.; Xie, W.; Kollmannsberger, C.; North, S.; Knox, J.J.; Lampard, J.G.; McDermott, D.F.; Rini, B.I.; Heng, D.Y.C. The impact of cytoreductive nephrectomy on survival of patients with metastatic renal cell carcinoma receiving vascular endothelial growth factor targeted therapy. J. Urol. 2011, 185, 60-66. [CrossRef]

19. Zhao, Z.; Wu, W.; Duan, X.; Zeng, G.; Liu, Y. The value of cytoreductive nephrectomy on the survival of metastatic renal carcinoma patients based on the number of site-specific metastases. PLOS ONE 2019, 14, e0215861. [CrossRef]

20. Mejean, A.; Thezenas, S.; Chevreau, C.; Bensalah, K.; Geoffrois, L.; Thiery-Vuillemin, A.; Cormier, L.; Lang, H.; Guy, L.; Gravis, G.; et al. Cytoreductive nephrectomy (CN) in metastatic renal cancer (mRCC): Update on Carmena trial with focus on intermediate IMDC-risk population. J. Clin. Oncol. 2019, 37, 4508. [CrossRef]

21. Motzer, R.J.; Mazumdar, M.; Bacik, J.; Berg, W.; Amsterdam, A.; Ferrara, J. Survival and prognostic stratification of 670 patients with advanced renal cell carcinoma. J. Clin. Oncol. Off. J. Am. Soc. Clin. Oncol. 1999, 17, 2530-2540. [CrossRef] [PubMed]

22. Bex, A.; Mulders, P.; Jewett, M.; Wagstaff, J.; van Thienen, J.V.; Blank, C.U.; van Velthoven, R.; Del Pilar Laguna, M.; Wood, L.; van Melick, H.H.E.; et al. Comparison of Immediate vs Deferred Cytoreductive Nephrectomy in Patients With Synchronous Metastatic Renal Cell Carcinoma Receiving Sunitinib: The SURTIME Randomized Clinical Trial. JAMA Oncol. 2019, 5, 164-170. [CrossRef] [PubMed]

23. Gerlinger, M.; Rowan, A.J.; Horswell, S.; Math, M.; Larkin, J.; Endesfelder, D.; Gronroos, E.; Martinez, P.; Matthews, N.; Stewart, A.; et al. Intratumor heterogeneity and branched evolution revealed by multiregion sequencing. N. Engl. J. Med. 2012, 366, 883-892. [CrossRef] [PubMed] 
24. Gerlinger, M.; Horswell, S.; Larkin, J.; Rowan, A.J.; Salm, M.P.; Varela, I.; Fisher, R.; McGranahan, N.; Matthews, N.; Santos, C.R.; et al. Genomic architecture and evolution of clear cell renal cell carcinomas defined by multiregion sequencing. Nat. Genet. 2014, 46, 225-233. [CrossRef] [PubMed]

25. Dadian, G.; Riches, P.G.; Henderson, D.C.; Taylor, A.; Moore, J.; Atkinson, H.; Gore, M.E. Immunological parameters in peripheral blood of patients with renal cell carcinoma before and after nephrectomy. Br. J. Urol. 1994, 74, 15-22. [CrossRef]

26. Renner, A.; Samtani, S.; Marín, A.; Burotto, M. Is Cytoreductive Nephrectomy Still a Standard of Care in Metastatic Renal Cell Carcinoma? J. Kidney Cancer VHL 2019, 6, 1-7. [CrossRef]

27. Shrimali, R.K.; Yu, Z.; Theoret, M.R.; Chinnasamy, D.; Restifo, N.P.; Rosenberg, S.A. Antiangiogenic agents can increase lymphocyte infiltration into tumor and enhance the effectiveness of adoptive immunotherapy of cancer. Cancer Res. 2010, 70, 6171-6180. [CrossRef]

28. Bex, A.; Haanen, J. Do targeted agents offer clinical benefit as presurgical therapy? World J. Urol. 2014, 32, 3-8. [CrossRef]

29. Gao, J.; Karam, J.A.; Tannir, N.M.; Campbell, M.T.; Slack Tidwell, R.; Ahrar, K.; Rao, P.; Ng, C.S.; Jonasch, E.; Matin, S.F.; et al. A pilot randomized study evaluating nivolumab (nivo) or nivo + bevacizumab (bev) or nivo + ipilimumab (ipi) in patients with metastatic renal cell carcinoma (MRCC) eligible for cytoreductive nephrectomy, metastasectomy or post-treatment biopsy (Bx). J. Clin. Oncol. 2019, 37, 4501. [CrossRef]

30. Buchler, T.; Klapka, R.; Melichar, B.; Brabec, P.; Dušek, L.; Vyzula, R.; Abrahamova, J. Sunitinib followed by sorafenib or vice versa for metastatic renal cell carcinoma-data from the Czech registry. Ann. Oncol. 2012, 23, 395-401. [CrossRef]

31. Poprach, A.; Bortlíček, Z.; Büchler, T.; Melichar, B.; Lakomý, R.; Vyzula, R.; Brabec, P.; Svoboda, M.; Dušek, L.; Gregor, J. Patients with advanced and metastatic renal cell carcinoma treated with targeted therapy in the Czech Republic: Twenty cancer centres, six agents, one database. Med. Oncol. 2012, 29, 3314-3320. [CrossRef] [PubMed]

(C) 2020 by the authors. Licensee MDPI, Basel, Switzerland. This article is an open access article distributed under the terms and conditions of the Creative Commons Attribution (CC BY) license (http://creativecommons.org/licenses/by/4.0/). 